\title{
Construção de Modelos 3D impressos como estratégia para a aprendizagem do conceito de interação enzima-substrato
}

\section{Construction of 3D Models printed as strategy for learning the concept of enzyme-substrate interaction}

\author{
Joyce Fernandes Almeida ${ }^{1 *}$, Keila Bossolani Kiill ${ }^{2}$ \\ ${ }^{1}$ Programa de Pós-Graduação em Educação, Grupo de Pesquisas em Educação em Ciências e Matemática, \\ Universidade Federal de Alfenas, MG; ${ }^{2}$ Programa de Pós-Graduação em Educação, Grupo de Pesquisas em \\ Educação em Ciências e Matemática, Instituto de Química, Universidade Federal de Alfenas, MG. \\ *e-mail: joycebioquimica@gmail.com
}

Support: UNIFAL-MG

\begin{abstract}
Resumo
No ensino de Bioquímica a compreensão da natureza tridimensional tem sido favorecida pelo uso de ferramentas de visualização e representação de conceitos e processos. Entre estas ferramentas encontram-se os modelos concretos, que permitem, além da aprendizagem conceitual, o desenvolvimento de habilidades visuais fundamentais para a transição entre o nível macroscópico e submicroscópico. Este trabalho tem como objetivo apresentar as contribuições da construção e do uso de modelos 3D impressos para a aprendizagem do conceito de interação enzima-substrato, pelos licenciandos em Química matriculados na disciplina obrigatória de Bioquímica. Desenhos foram utilizados para investigar a ideia de "interação enzima-substrato", no início e no final de uma sequência de atividades de modelagem 3D realizadas pelos licenciandos. A análise do uso dos modelos 3D impressos no processo de ensino e aprendizagem do conceito de interação enzima-substrato foi realizada comparando-se os elementos codificados nos desenhos antes e após a participação nas atividades de modelagem 3D. Os resultados apontam que a participação dos estudantes na construção dos modelos 3D impressos contribuiu para a percepção de aspectos químicos da interação enzima-substrato, no sentido de compreender a complexidade do fenômeno em questão.
\end{abstract}

Palavras-chave: ensino de bioquímica; modelos 3D impressos; modelagem 3D; interação enzima-substrato

\begin{abstract}
In the teaching of biochemistry the understanding of three dimensional nature has been favored by the use of visualization tools and representation of concepts and processes. Among these tools are the concrete models that allow, in addition to conceptual learning, the development of visual skills fundamental to the transition between the macroscopic and submicroscopic level. This work aims to present the contributions of the construction and use of $3 D$ printed models for the learning of the concept of enzyme-substrate interaction, by the chemistry graduates enrolled in the compulsory discipline of Biochemistry. Drawings were used to investigate the idea of "enzymesubstrate interaction" at the beginning and end of a sequence of $3 D$ modeling activities carried out by students. The analysis of the use of $3 D$ printed models in the teaching and learning process of the concept of enzymesubstrate interaction was performed by comparing the elements coded in the drawings before and after participating in 3D modeling activities. The results show that students' participation in the construction of 3D printed models contributed to the perception of chemical aspects of the enzyme-substrate interaction, in order to understand the complexity of the phenomena in question.
\end{abstract}

Keywords: biochemistry teaching; 3D printed models; 3D modeling; enzyme-substrate interaction 
National award: Construction of 3D Models printed as strategy for learning the concept of enzyme-substrate interaction

\section{Ficha da atividade}

\begin{tabular}{|c|c|}
\hline Título & $\begin{array}{l}\text { Construção de modelos 3D impressos como estratégia para a aprendizagem do } \\
\text { conceito de interação enzima-substrato }\end{array}$ \\
\hline Categoria: & Prática de Ensino \\
\hline Tipo & Prática de ensino: construção de modelos 3D impressos. \\
\hline Público-alvo: & Estudantes de graduação que estejam cursando a disciplina de Bioquímica. \\
\hline $\begin{array}{l}\text { Conteúdos } \\
\text { abordados }\end{array}$ & Interação enzima-substrato. \\
\hline $\begin{array}{l}\text { Objetivos } \\
\text { educacionais }\end{array}$ & $\begin{array}{l}\text { Aprendizagem significativa do conceito de interação enzima-substrato por meio } \\
\text { da elaboração, teste e avaliação dos modelos 3D impressos. }\end{array}$ \\
\hline Duração & 7 horas, aproximadamente. \\
\hline $\begin{array}{l}\text { Materiais } \\
\text { utilizados }\end{array}$ & $\begin{array}{l}\text { Impressora 3D (disponível na universidade para atividades de ensino e } \\
\text { pesquisa), um cartucho do material PLA (ácido polilático); cartolina; papel de } \\
\text { seda; imãs; tintas; cola quente; tesoura; pincéis. }\end{array}$ \\
\hline Criação & Data de criação $(08 / 05 / 2018)$ \\
\hline Aplicação & Data de aplicação/ avaliação (12/07/2018) \\
\hline
\end{tabular}


National award: Construction of 3D Models printed as strategy for learning the concept of enzyme-substrate interaction

\section{Introdução}

$\mathrm{Na}$ perspectiva de Blanco-Anaya, Justi e Bustamante [1], modelos são representações parciais de ideias, objetos ou fenômenos, elaborados com um ou mais objetivos específicos. Na aprendizagem Química, estes recursos têm sido utilizados como forma de contribuir para o processo de ensino e de aprendizagem, no sentido de favorecer o desenvolvimento de habilidades visuais ${ }^{1}$, que permitem estabelecer a transição entre o nível macroscópico e submicroscópico [2].

Justi [3] aponta que muitas vezes, os modelos são compreendidos, equivocadamente, como sendo "cópias da realidade" pelo fato de poderem ser construídos a partir de "coisas" externas à mente do indivíduo. Entretanto, pelo contrário os modelos são "representações parciais" construídas pela mente humana e têm limitações. Em outro trabalho, Justi [4] também afirma que um modelo pode ser modificado. O entendimento de tais premissas pode evitar erros conceituais como, por exemplo, o estudante pensar que os modelos da interação enzima-substrato desenhados nos livros são ampliações do fenômeno, ou que o modelo mais recente proposto pela ciência (modelo de ajuste-induzido) é perfeito.

A Ciência Cognitiva considera as ideias internas à mente do indivíduo como sendo modelos mentais. Tais modelos podem ser externalizados por meio dos modelos expressos e revelar como o indivíduo pensa ou entende determinado conceito científico [5]. Os modelos expressos, por sua vez, podem ser construídos individualmente ou em grupo e se tornar um modelo consensual, quando um modelo expresso for escolhido em consenso pelos membros de um determinado grupo. Entretanto, se o modelo consensual for aceito por um grupo de cientistas com o objetivo de contribuir para a construção de conhecimento, este pode ser considerado como sendo um modelo científico [4].

Para Justi $[4,6]$ as primeiras etapas do processo de construção dos modelos consistem na definição dos objetivos da entidade a ser modelada e da escolha de um ou mais modos de representação, os quais podem ser: concreto, verbal, matemático, visual ou gestual. Para a autora os modos de representação podem ser combinados ou não. No caso de haver combinação do modo concreto de representação com elementos visuais, verbais e/ou matemáticos o modelo é chamado de concreto misto, por exemplo, o modelo concreto do sistema solar com etiquetas explicativas.

1Habilidades visuais na perspectiva de Ferreira e Arroio [7] compreendem habilidades de visualização espacial, orientação espacial e relações espaciais, fundamentais para compreensão adequada das informações contidas nas representações. 
National award: Construction of 3D Models printed as strategy for learning the concept of enzyme-substrate interaction

O modelo concreto recebe maior atenção pelo fato de ser o modo de representação do modelo 3D impresso, objeto de investigação da presente proposta de prática de ensino. O modelo $3 \mathrm{D}$ impresso pode ser caracterizado como sendo uma representação tridimensional elaborado a partir de materiais resistentes como, por exemplo, o modelo de plástico colorido do modelo atômico de Bohr impresso por Smiar e Mendez [8].

A elaboração e o uso de modelos 3D impressos iniciou no final da década de 1980, favorecendo diferentes áreas, como a medicina, a odontologia, a arqueologia e a educação, em particular [9]. Nos últimos anos esta tecnologia tem sido amplamente explorada no ensino de Química e Bioquímica [10, 11, 12, 13, 14]. Os modelos 3D impressos são utilizados por professores, pesquisadores e estudantes, principalmente como um recurso para o ensino de conceitos complexos e abstratos [15].

O conceito de interação enzima-substrato é focalizado neste estudo por ser considerado um conceito abstrato e que muitos estudantes apresentam dificuldade de compreensão e representação. Estudos de autores como Linenberger e Bretz [16] e Sangiogo e Zanon [17] também apontam a interação enzima-substrato como sendo um dos conceitos que os estudantes mais apresentam ideias equivocadas. Ainda que existam modelos científicos que explicam a interação enzima-substrato, como o modelo chavefechadura e o modelo de ajuste induzido ${ }^{2}$, não há relatos na literatura sobre a elaboração de modelos concretos para aprendizagem desse conceito.

Nesta perspectiva, modelos 3D impressos que explicam a interação enzimasubstrato foram construídos por meio da modelagem $3 \mathrm{D}^{3}$. A modelagem é entendida aqui enquanto um processo de ensino, "pelo qual os estudantes constroem seus próprios modelos, o que Ihes permite explicar e prever fenômenos" [18]. Para Justi e Gilbert [19] o processo de modelagem deve envolver, fundamentalmente, as etapas de elaboração, expressão, teste e avaliação de uma determinada representação de um conceito ou fenômeno, as quais servirão de base para a construção dos modelos.

Estudos internacionais recentes apontam experiências em relação à elaboração e ao uso de modelos 3D impressos como estratégia inovadora e eficaz para o ensino e a aprendizagem de conceitos bioquímicos [8, 20, 21, 22, 23]. Dentre as contribuições do uso de modelos 3D impressos no contexto do ensino de Bioquímica, destacam-se: a

20 modelo de ajuste induzido é atualmente o modelo cientificamente aceito para explicação da interação enzima-substrato. Entretanto, na maioria dos livros didáticos o modelo chave-fechadura ainda é o mais empregado para representar o conceito $[16,17]$.

3Modelagem 3D pode ser entendida a partir da adaptação do significado de modelagem escolar, como sendo um processo de construção de modelos 3D por meio do uso da impressora 3D [18]. 
National award: Construction of 3D Models printed as strategy for learning the concept of enzyme-substrate interaction

elaboração de um espectrofotômetro em 3D para o ensino de propriedades cinéticas e ópticas [10]; ensino do conteúdo de geometria molecular, conformação e estereoquímica [11]; a impressão de modelos moleculares 3D de estruturas de cristalografia de raio- $x$ de enzimas disponíveis em bancos de dados [14] e a construção de modelos 3D impressos de proteínas durante uma atividade experimental para explorar a relação entre a estrutura e a função de proteínas [22] (Figura 1). Outros autores afirmam que a impressão 3D pode ser uma alternativa inovadora e financeiramente viável às instituições de ensino, já que o processo de elaboração dos modelos é considerado simples e os custos dos materiais é relativamente baixo $[22,24]$.

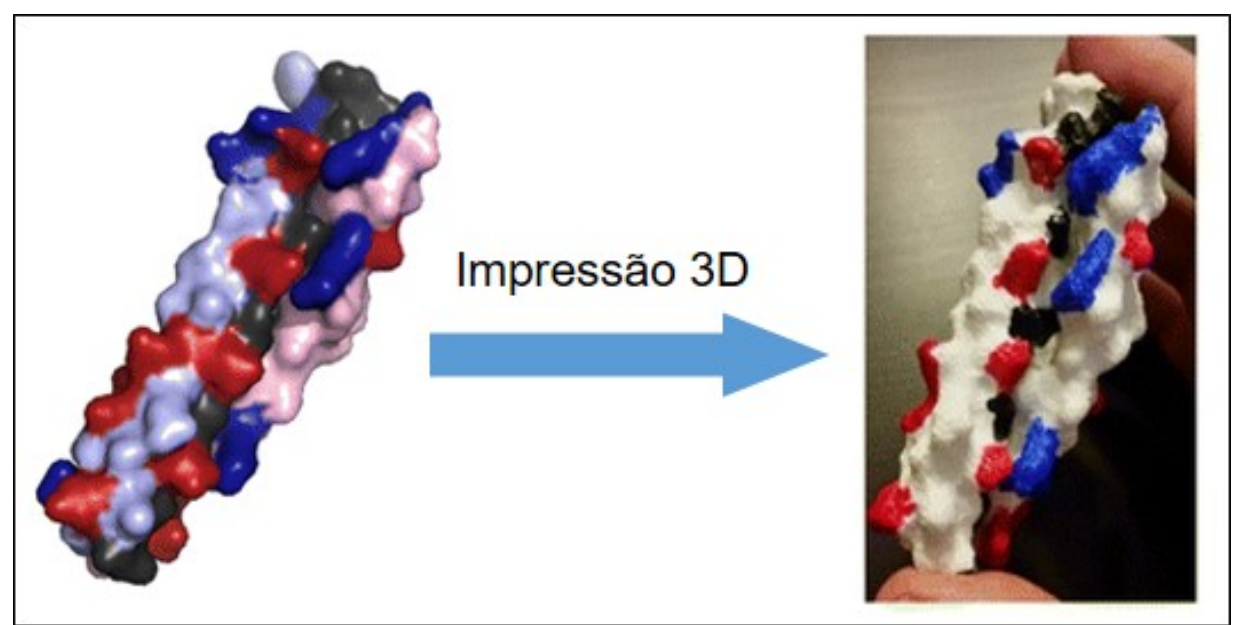

Figura 1. Modelo 3D impresso de um experimento que explorou a relação entre a estrutura e a função de proteínas elaborado por Meyer [22]. Fonte: extraído de Meyer [22].

Contudo, no Brasil investigações científicas envolvendo a construção e o uso de modelos 3D impressos ainda é um assunto pouco explorado e não existem relatos na literatura sobre a elaboração de modelos 3D impressos para o ensino de Bioquímica. Mediante a essa lacuna na literatura brasileira, o objetivo do presente trabalho foi apresentar o processo de elaboração de modelos 3D impressos como uma potencial prática de ensino que buscou contribuir para a aprendizagem do conceito de interação enzima-substrato.

\section{Desenvolvimento}

O processo de construção dos modelos $3 \mathrm{D}$ impressos seguiu as etapas da modelagem propostas por Justi [4, 6]. A primeira etapa consistiu na elaboração dos modelos mentais para a investigação do conhecimento prévio dos estudantes sobre o conceito de interação enzima-substrato. Esta atividade foi realizada por meio da 
National award: Construction of 3D Models printed as strategy for learning the concept of enzyme-substrate interaction

elaboração de desenhos pelos estudantes, respondendo à seguinte tarefa: "Elabore um desenho que represente a interação que ocorre entre a enzima e o substrato. Sua representação é livre. Use sua criatividade". Em um primeiro momento os desenhos foram elaborados individualmente. Em seguida, foram formados cinco grupos com três estudantes e cada grupo escolheu, em consenso entre seus membros, um desenho que consideraram que melhor representava a interação enzima-substrato.

A segunda etapa se referiu à expressão dos modelos 3D a partir dos modelos mentais dos estudantes, os quais foram externalizados por meio de desenhos. Os modelos 3D foram elaborados com base nos desenhos escolhidos pelos grupos de estudantes (modelos consensuais). Para a elaboração dos modelos 3D foi utilizado o software AutoCad ${ }^{\circledR 4}$. Informações sobre os comandos utilizados na elaboração e na impressão dos modelos 3D são detalhados nos apêndices A e B.

A partir da análise dos modelos consensuais, observou-se que as representações (desenhos) não estavam de acordo com o modelo cientificamente aceito para explicação da interação enzima-substrato. Neste caso foram propostas atividades de intervenção para superar as dificuldades apresentadas pelos estudantes. Dentre os recursos utilizados para o planejamento das intervenções, destacam-se: os softwares educacionais livres; as representações em 2D e 3D; e três mecanismos de ação de enzimas ${ }^{5}$. Os materiais que foram utilizados durante as intervenções podem ser obtidos na seção materiais adicionais.

O objetivo principal das atividades de intervenção foi associar o uso dos modelos 3D impressos com outras ferramentas para visualização (softwares e imagens 2D e 3D) e retomada do conteúdo de enzimas. Após a retomado do conteúdo, os estudantes participaram de uma segunda atividade, cujo objetivo foi apresentar três diferentes mecanismos de ação de enzimas. Durante esta atividade os estudantes realizaram a análise e identificação dos aspectos químicos comuns entre os três mecanismos de ação enzimáticas propostos. É importante ressaltar que a realização das atividades de intervenção foi fundamental para reflexão e reelaboração das ideias dos estudantes sobre o conceito de interação enzima-substrato.

A terceira etapa consistiu no teste dos modelos elaborados. Nesta etapa tanto as representações elaboradas (desenhos) como os modelos 3D impressos foram

$4 \quad$ O software AutoCad ${ }^{\circledR}$ está disponível para estudantes e professores e seu download pode ser realizado no site da Autodesk.

5 Os mecanismos de ação das enzimas utilizados durante as atividades de intervenção foram: da quimotripsina descrito por Zangiogo e Zanon [17], das lipases proposto por Vaz e Choupina [25] e das proteases virais elaborado por Muri [26]. 
apresentados aos estudantes. Em seguida foi realizada a comunicação dos modelos iniciais aos membros do grupo. Durante a atividade os grupos interagiram de forma dinâmica e apresentaram as similaridades, bem como as contradições do modelo expresso escolhido pelo grupo em relação ao modelo aceito pela ciência. Apresenta-se na Figura 2 o modelo 3D impresso de ajuste induzido elaborado com base na representação visual proposta por Linenberger e Bretz [16]. No final da atividade foram realizadas discussões e a socialização dos modelos elaborados pelos grupos com o restante da turma.
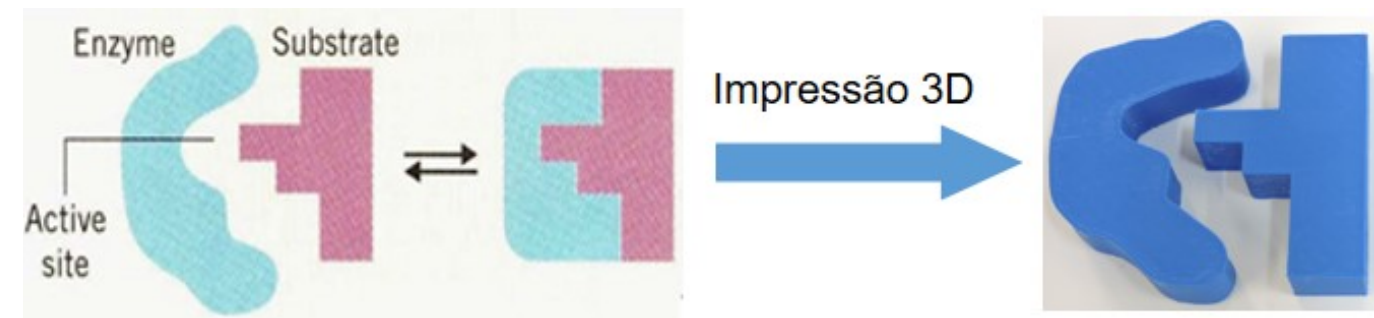

Figura 2. Modelo 3D impresso de ajuste induzido elaborado com base na representação apresentada por Linenberger e Bretz [16].

A atividade de teste dos modelos foi realizada por meio da comparação dos aspectos químicos comuns dos modelos 3D impressos com o modelo proposto pela ciência. Os seguintes aspectos químicos foram considerados: interações químicas, especificidade, presença de sítio ativo, mudança conformacional, atividade cíclica da enzima e transformações químicas [17]. Estes testes foram realizados de maneira empírica por meio da socialização dos modelos entre os grupos.

A última etapa se referiu à avaliação dos modelos quanto as suas abrangências e limitações. Nesta atividade os estudantes avaliaram a coerência dos modelos com os seus objetivos, no sentido de compreender se o modelo elaborado poderia ser ou não utilizado para explicar o conceito de interação enzima-substrato. Além disso, estes estudantes sugeriram adaptações aos modelos 3D impressos, a partir da utilização de materiais como, por exemplo, uso de etiquetas de papel e imãs. Este material foi fornecido aos estudantes durante a atividade de intervenção. As adaptações dos modelos realizadas pelos próprios estudantes foi uma tentativa de reduzir suas limitações, isso em termos da explicação bioquímica adequada para a aprendizagem do conceito em questão.

\section{Procedimento para a aplicação da atividade}

As atividades de modelagem foram aplicadas com 15 estudantes do curso de Licenciatura em Química da Universidade Federal de Alfenas, matriculados na disciplina 
National award: Construction of 3D Models printed as strategy for learning the concept of enzyme-substrate interaction

de Laboratório de Ensino de Química II e na disciplina de Bioquímica ${ }^{6}$. É importante ressaltar que, durante o processo de modelagem, os modelos $3 \mathrm{D}$ impressos foram reelaborados, já que a avaliação dos modelos iniciais elaborados pelos estudantes indicou algumas dificuldades de aprendizagem.

De acordo com Justi [6] não existe uma sequência de etapas predeterminada para a construção dos modelos, contudo, o professor deve planejar suas atividades adotando, fundamentalmente, as etapas de elaboração, expressão, teste e avaliação dos modelos. Nesta perspectiva, o professor também deve esclarecer aos estudantes os significados de cada uma das etapas do processo de construção dos modelos, bem como, discutir a relação entre elas. Outro aspecto fundamental da modelagem é que os modelos mentais dos estudantes devem ser investigados no início do processo de modelagem e antes do planejamento de atividades de intervenção. Considerando a importância de identificar as ideias que os estudantes têm em sua mente, a elaboração de desenhos no início e após as etapas da modelagem podem servir de feedback dos estudantes ao professor.

No decorrer das atividades propostas para a modelagem, os estudantes precisam estar envolvidos e participar ativamente do processo, elaborando ou reformulando seus modelos inicias, favorecendo discussões entre os membros do seu grupo, visando construir um modelo 3D que mais se aproxima do modelo cientificamente aceito. Esta interação pode ser obtida pela comparação entre os aspectos químicos representados ou não nos modelos. Por outro lado, o professor deve elaborar perguntas e propor argumentações durante as atividades, por exemplo, questionar qual (is) aspectos químicos foram considerados ou não durante a elaboração do modelo.

\section{Procedimentos de avaliação}

Em um primeiro momento todos os desenhos foram avaliados pelos estudantes, buscando comparação dos aspectos químicos comuns entre os desenhos e o modelo cientificamente aceito. De modo semelhante, a avaliação dos modelos 3D impressos foi realizada em duplicata durante a etapa de teste e avaliação dos modelos e consistiu na identificação pelos próprios estudantes dos aspectos químicos comuns codificados em seus modelos. A atividade foi gravada e, posteriormente, transcrita.

Para isso os estudantes responderam, de forma oral, a um roteiro de perguntas (Apêndice $C$ ). Com base na avaliação das abrangências e limitações dos modelos 3D impressos, os estudantes apresentaram sugestões de adaptações e materiais para os modelos elaborados, buscando uma aproximação com o modelo cientificamente aceito.

6 Com exceção de um estudante que já havia cursado a disciplina de Bioquímica. 
National award: Construction of 3D Models printed as strategy for learning the concept of enzyme-substrate interaction

\section{Potencial educacional}

A participação ativa dos estudantes nas atividades da modelagem 3D possibilitou a construção de modelos 3D impressos para serem utilizados como recursos didáticos para aprendizagem do conceito de interação enzima-substrato. Em termos didáticopedagógicos o processo de elaboração dos modelos 3D impressos contribuiu para o desenvolvimento de habilidades de visualização e, consequentemente, de representação da interação enzima-substrato.

Estes estudantes elaboraram os modelos 3D impressos por meio das suas próprias representações (desenhos), os quais potencializaram a aquisição de significado e a prática de construção de conhecimento. Os modelos 3D impressos podem ser considerados como sendo uma estratégia eficaz e inovadora em comparação aos modelos visuais já disponíveis na literatura. Além disso, a atividade proposta para a elaboração dos modelos 3D demonstrou ser uma estratégia de ensino acessível à estudantes e professores.

\section{Diferencial com as atividades/materiais preexistentes}

A combinação entre atividades de ensino de Bioquímica baseadas na elaboração de modelos 3D impressos com atividades de modelagem 3D pode ser considerada como uma temática inovadora em pesquisas brasileiras. Tendo em vista os estudos na literatura que evidenciaram o uso de representações para a aprendizagem do conceito de interação enzima-substrato, não há um modelo concreto para aprendizagem deste conceito $[8,20$, $21,22,23]$.

Dentre as características que diferenciam os modelos $3 \mathrm{D}$ impressos dos materiais preexistentes, destaca-se: o material utilizado para a impressão PLA - ácido polilático (plástico biodegradável derivado do amido de milho) [9], a possibilidade de impressão de estruturas complexas [10] e a interface com a modelagem científica que pode estimular a experiência prática dos estudantes com a visão tridimensional [24].

Em contrapartida, considera-se algumas limitações do uso de modelos 3D impressos, tais como: restrição das dimensões dos modelos que pode variar de acordo com o modelo da impressora (neste caso o tamanho máximo foi de $14 \times 14 \times 14 \mathrm{~cm}$ ), rigidez do material à temperatura ambiente, tempo de impressão (de cerca de uma a três horas), custo e falha operacional. Contudo, de acordo com Smiar e Mendez [8] e Canessa [9] 
National award: Construction of 3D Models printed as strategy for learning the concept of enzyme-substrate interaction

algumas destas limitações podem ser superadas com medidas simples como, por exemplo, a impressão dos modelos em peças separadas pode ampliar o número de montagens e a projeção de peças de tamanhos reduzidos pode contribuir para a diminuição dos custos com material e tempo de impressão. Além disso, o uso de geradores pode evitar falhas operacionais em casos de interrupção da energia elétrica.

É importante destacar a importância do papel do professor em esclarecer possíveis incoerências em relação à natureza dos modelos na Ciência [4, 7]. Outrossim, o professor deve ressaltar que os modelos 3D impressos não são cópias do que acontece na realidade durante a atividade enzimática, pelo contrário, são representações parciais da interação enzima-substrato e que possuem limitações. Esta ação reforça o significado de que pode ou não existir semelhança entre o modelo 3D impresso e a ideia a ser modelada (interação enzima-substrato).

Uma das limitações da natureza dos modelos 3D impressos para a aprendizagem do conceito de interação enzima-substrato seria a relação do tamanho real da enzima e do substrato. Contudo, tal limitação poderia ser minimizada com base na comparação entre as dimensões de tamanho dos modelos 3D impressos obtidos a partir de modelos mentais com modelos 3D de enzimas já conhecidas como, por exemplo, da estrutura 3D da enzima peroxidase proposta por Jones [14].

Os resultados aqui apresentados são um recorte de uma pesquisa de mestrado que apontou algumas contribuições do uso de modelos 3D impressos para a aprendizagem do conceito de interação enzima-substrato pelos licenciandos em Química da UNIFAL-MG. No decorrer das atividades de modelagem 3D, buscou-se oferecer condições para que os estudantes pudessem repensar e reelaborar seus modelos iniciais. Além disso, a avaliação dos modelos 3D impressos pelos próprios estudantes contribuiu para reflexão do uso do modelo chave-fechadura, no sentido que favoreceu discussões sobre as limitações desses modelos, bem como sua aplicação para o ensino de Bioquímica.

\section{Resultados da avaliação}

Os modelos 3D impressos foram elaborados e avaliados por 15 estudantes. Todas as atividades de intervenção foram planejadas com o professor responsável pela disciplina de Bioquímica. Para garantir a confiabilidade e fidedignidade da pesquisa foi realizada a validação consensual ${ }^{7}$. Três professores pesquisadores participaram como

7 A validação consensual se baseia em uma técnica em que os instrumentos da pesquisa são validados 
National award: Construction of 3D Models printed as strategy for learning the concept of enzyme-substrate interaction

voluntários da etapa de validação consensual. A investigação teve início após a regência da aula sobre o conteúdo de enzimas da disciplina de Bioquímica.

Para a etapa de avaliação tanto os modelos 3D impressos iniciais como os modelos 3D finais foram analisados, de forma que os estudantes identificaram os aspectos químicos comuns entre os modelos. Apresenta-se na Figura 3 a frequência dos aspectos químicos codificados nos modelos 3D inicial e final.

\section{Frequência dos aspectos químicos codificados nos modelos 3D inicial e final}

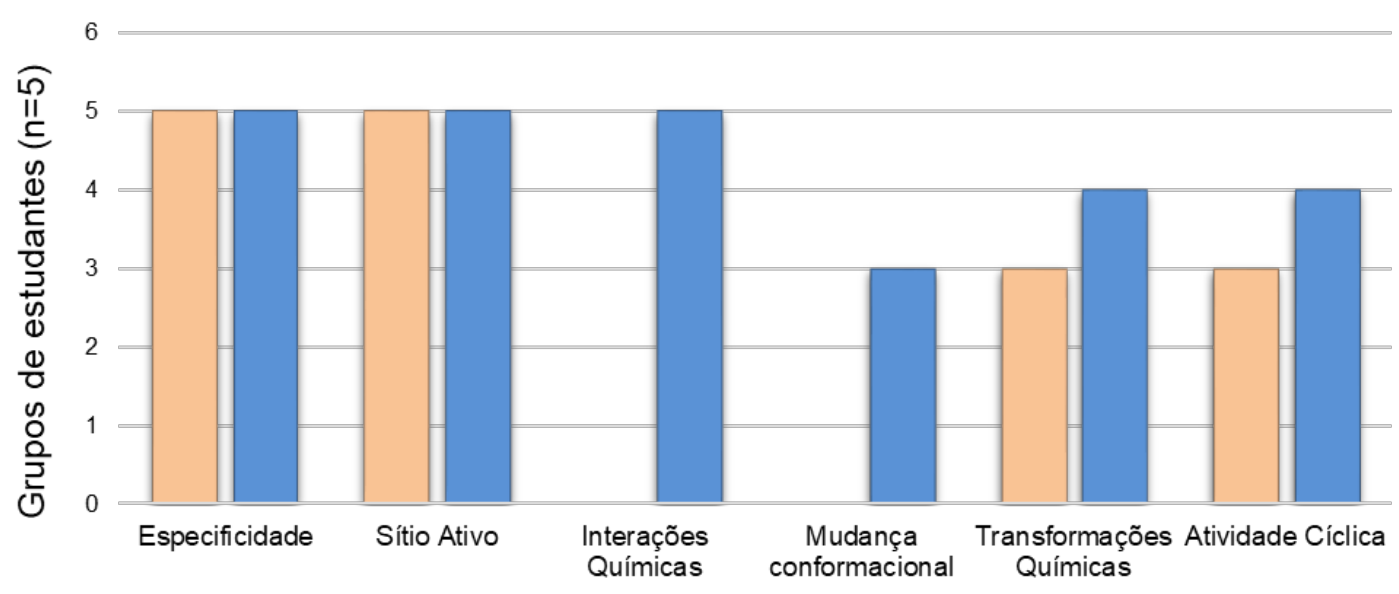

Aspectos químicos codificados

\section{$\square \mathrm{Ml} \square \mathrm{MF}$}

Figura 3. Frequência dos aspectos químicos codificados nos modelos 3D inicial (MI) e final (MF).

Todos os grupos de estudantes representaram inicialmente a interação enzimasubstrato por meio do modelo chave-fechadura. Apresenta-se na Figura 4A a representação da interação enzima-substrato e na Figura 4B o modelo 3D inicial elaborado pelo Grupo 5.

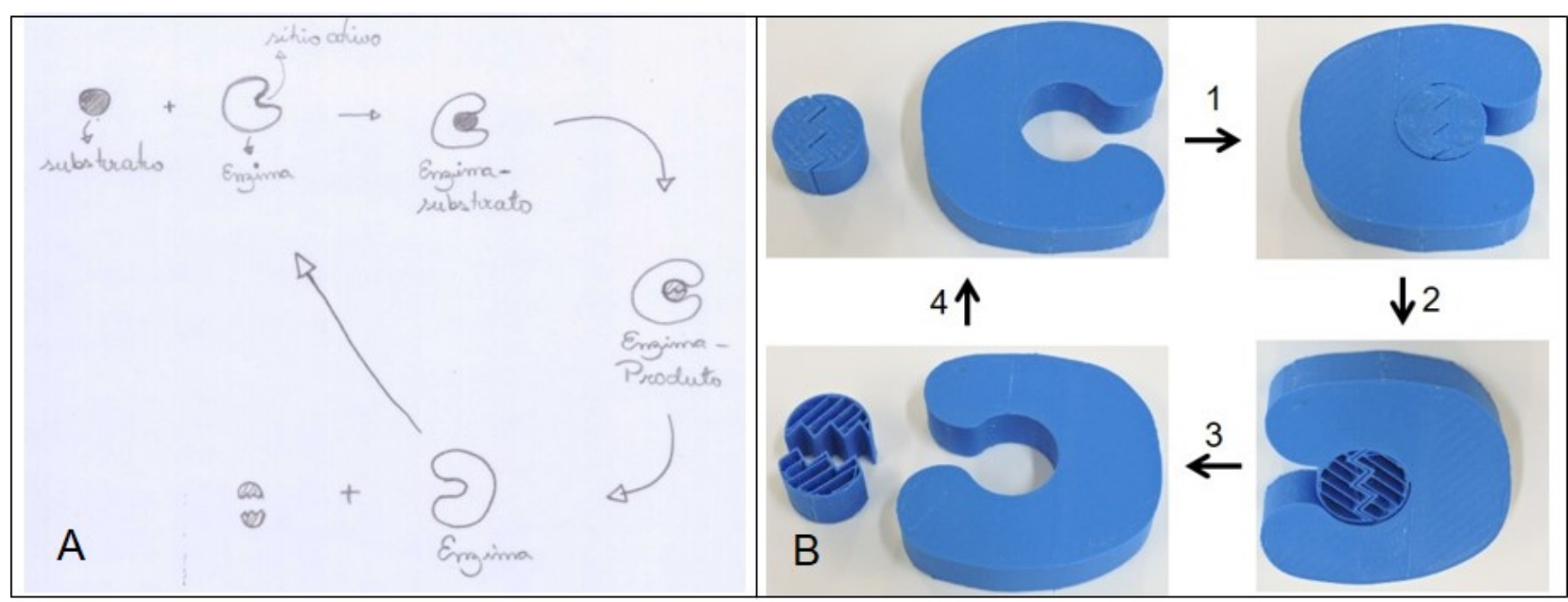

Figura 4. A) Representação da interação enzima-substrato escolhida pelo Grupo 5. B) Modelo 3D inicial elaborado pelo Grupo 5.

por especialistas que buscam uma concordância nas categorizações estabelecidas [27]. 
National award: Construction of 3D Models printed as strategy for learning the concept of enzyme-substrate interaction

Nestes modelos iniciais, a especificidade e a presença do sítio ativo foram os aspectos químicos considerados por todos os grupos de estudantes. As transformações químicas e a atividade cíclica da enzima somente foram consideradas por três, dos cinco grupos. Entretanto, nenhum dos grupos de estudantes representou nos modelos 3D iniciais as interações químicas e a mudança conformacional da enzima.

Em contrapartida, tanto os desenhos como os modelos 3D impressos reelaborados após as atividades de modelagem 3D apresentaram um avanço em termos da representação dos aspectos químicos da interação enzima-substrato. A maior parte dos grupos representou em seus modelos 3D finais aspectos como, a especificidade, o ciclo da atividade enzimática, sobretudo, a mudança conformacional na região do sítio ativo da enzima e transformações químicas, os quais não haviam sido representados no modelo 3D inicial. Apresenta-se na Figura 5A e 5B a representação da interação enzima-substrato reelaborado pelo Grupo 5 e o modelo 3D reelaborado pelo Grupo 5, respectivamente.

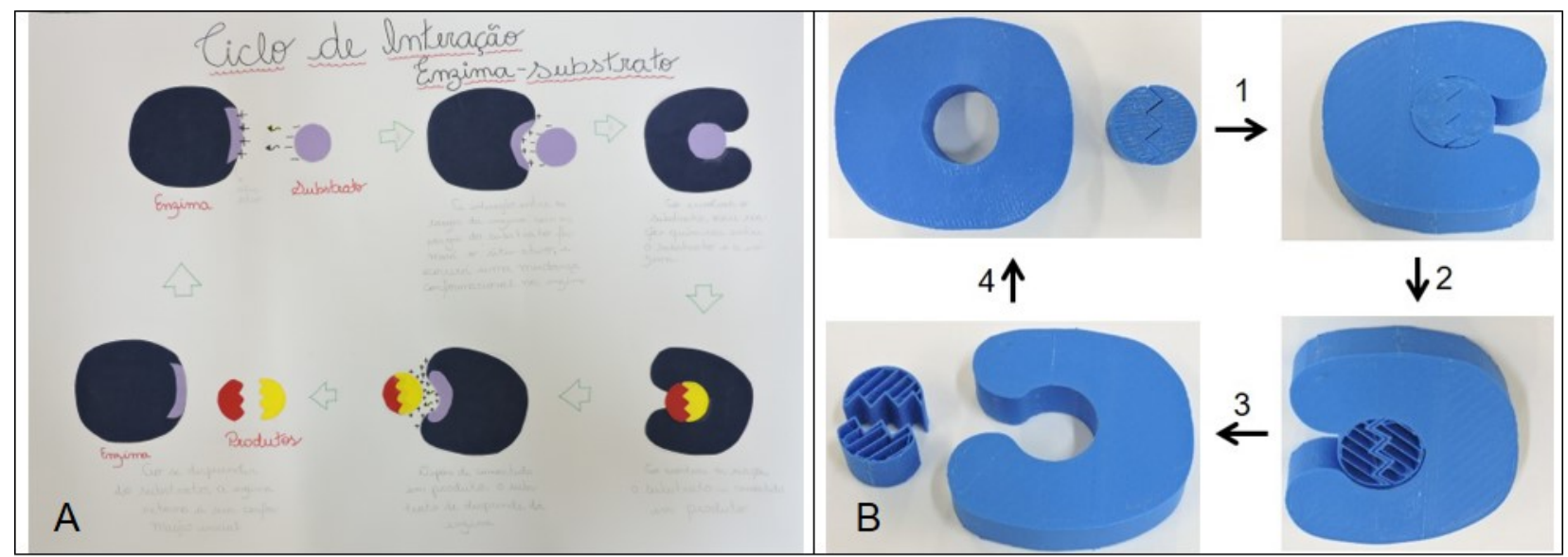

Figura 5. A) Representação da interação enzima-substrato reelaborada pelo Grupo 5. B) Modelo 3D final elaborado pelo Grupo 5.

A Figura 5A conteve algumas descrições, que seguem: "as interações entre as cargas da enzima com as cargas do substrato formarão o sítio ativo, e ocorrerá uma mudança conformacional na enzima. Ao envolver o substrato, ocorre reações químicas entre o substrato e a enzima. Ao acontecer as reações o substrato é convertido em produto. Depois de convertido em produto, o substrato se desprende da enzima. Ao se desprender do substrato, a enzima retorna a sua conformação inicial” (E11, Grupo 5).

Nota-se que os estudantes passaram a representar a interação enzima-substrato pelo modelo de ajuste induzido, considerando aspectos macroscópicos e submicroscópicos durante a explicação do desenho (Figura 5A), o que leva a crer que estes estudantes relacionaram as principais ideias trabalhadas durante as atividades de modelagem 3D e elaboraram modelos coerentes com a explicação do conceito em 
National award: Construction of 3D Models printed as strategy for learning the concept of enzyme-substrate interaction

questão.

A comparação entre os modelos 3D inicial e final elaborados pelo Grupo 2 (Figuras $6 \mathrm{~A}$ e 6B) também aponta resultados satisfatórios em relação ao desenvolvimento de habilidades visuais durante a participação dos estudantes no processo de modelagem 3D, uma vez que todos os seis aspectos químicos da interação enzima-substrato analisados (Figura 3) foram representados no modelo 3D impresso final. Apresenta-se na Figura 5B o modelo 3D impresso reelaborado pelo Grupo 2.

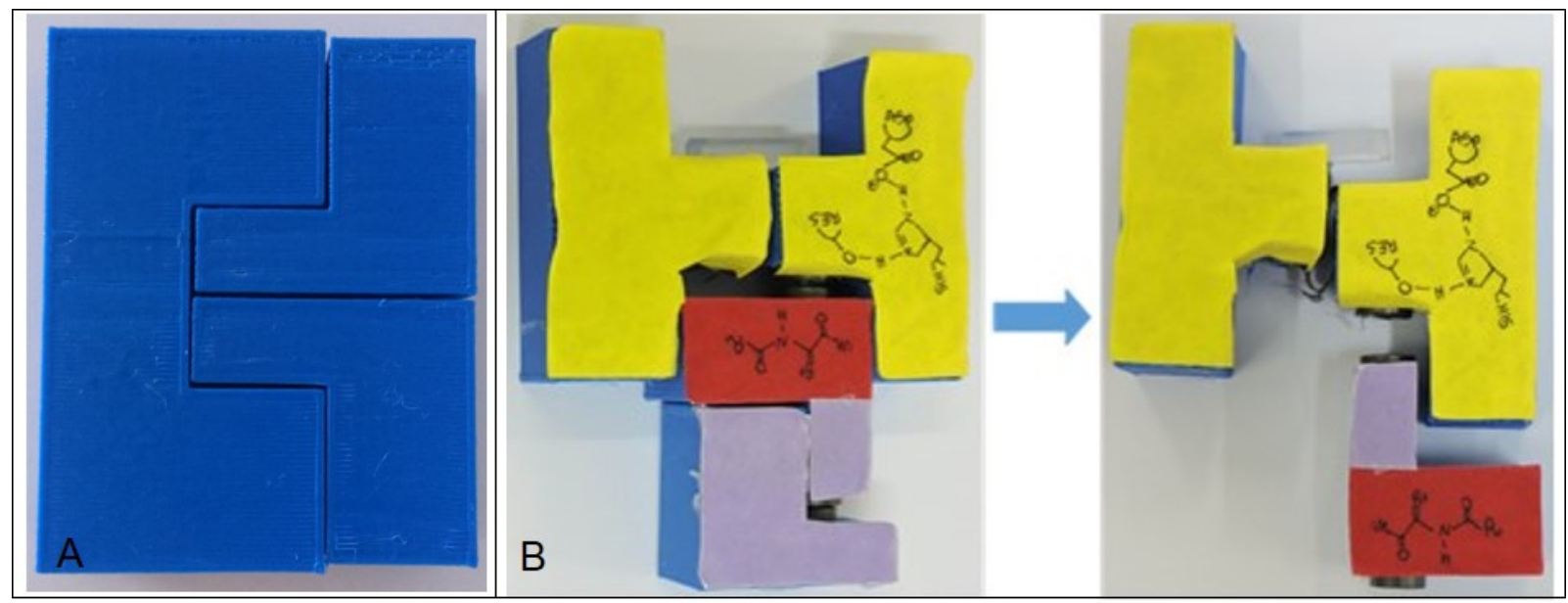

Figura 6. A) Modelo 3D inicial elaborado pelo Grupo 2. B) Modelo 3D final elaborado pelo Grupo 2.

Os integrantes do Grupo 2 sugeriram o uso de materiais para adaptações do modelo 3D (Figura 6B), com o objetivo de aproximá-lo do modelo cientificamente aceito para a explicação do conceito de interação enzima-substrato. Destaca-se que o modelo 3D impresso final foi utilizado para explicar as interações químicas eletrostáticas (representadas pelos imãs); a mudança de conformação na região do sítio ativo da enzima (representado em amarelo) quando o substrato se aproxima (representada pelo movimento entre as peças da enzima em função do uso de um fragmento de cola quente) e a possível interação de cofatores (representado em lilás).

Nota-se pela comparação dos modelos 3D impressos inicial e final que algumas habilidades visuais desenvolvidas durante a sequência de atividades de intervenção podem ter contribuído para a transição de ideias entre os níveis macroscópicos e submicroscópicos. A análise dos modelos 3D impressos demonstrou que, antes da participação nas atividades de modelagem 3D, os estudantes apresentaram uma ideia equivocada da interação enzima-substrato.

A ideia da interação enzima-substrato como sendo um "quebra-cabeça" ou "encaixe físico-mecânico" foi sendo superada no decorrer das atividades, no sentido que estes estudantes passaram a pensar a interação enzima-substrato como sendo um 
National award: Construction of 3D Models printed as strategy for learning the concept of enzyme-substrate interaction

processo não estático e dinâmico, o qual envolve transformações químicas complexas. Apresenta-se na seção materiais adicionais as imagens dos modelos 3D elaborados pelos demais grupos.

\section{Considerações finais}

Os resultados obtidos durante o processo de construção dos modelos 3D impressos evidenciaram seu potencial como atividade didática e inovadora a ser explorada por docentes e estudantes de Bioquímica. Os modelos 3D reelaborados sugerem que os estudantes apresentaram um avanço na aprendizagem em termos da representação de aspectos químicos nos níveis macroscópicos e submicroscópicos, principalmente a capacidade de previsão da mudança na conformação da enzima.

O planejamento desta atividade foi idealizado para aprendizagem do conceito de interação enzima-substrato pelos estudantes ao longo de uma disciplina de Laboratório de Ensino de Química II, que estavam matriculados na disciplina de Bioquímica. Esta é uma proposta de atividade de ensino que pode ser utilizada em qualquer curso de graduação que tenha a disciplina de Bioquímica em sua matriz curricular. Apesar de ter sido uma atividade viabilizada pela disponibilidade da impressora 3D pela instituição, futuras parcerias entre universidades e escolas de ensino médio podem facilitar o acesso a este tipo de ferramenta para pesquisas no contexto do ensino médio e superior.

\section{Referências}

[1] Blanco-Anaya P, Justi R, Bustamante JD. Challenges and opportunities in analysing students modelling. Int. J. Sci. Educ. 2017; 39(3): 377-402.

[2] Gilbert JK, Treagust. Ferreira CR, Arroio A, Bustamante JD. Multiple representations in chemical education. Int. J. Sci. Educ. 2009; 31(16): 2271-2273.

[3] Justi R. La enseñanza de ciências basada em la elaboración de modelos. Enseñanza de Las Ciencias. 2006; 24(2): 173-184.

[4] Justi R. Modelos e modelagem no ensino de química. In: Santos WLP, Maldaner OA, (Org.). Ensino de Química em Foco. Rio Grande do Sul: Unijuí; 2010.

[5] Lee SW-Y, Chang H-Y, Wu H-K. Students' views of scientific models and modeling: do representational characteristics of models and students' educational levels matter?. Research in Science Education. 2015; 47(2): 305-328.

[6] Justi R. Relações entre argumentação e modelagem no contexto da ciência e do ensino de ciências. Ensaio Pesquisa e Educação em Ciências. 2015; 17(n. especial): 31-48.

[7] Ferreira CR, Arroio A, Bustamante JD. Visualizações no ensino de química: concepções de professores em formação inicial. QNEsc. 2013; 35(3): 199-208. 
National award: Construction of 3D Models printed as strategy for learning the concept of enzyme-substrate interaction

[8] Smiar K, Mendez JD. Creating and using interactive, 3D-printed models to improve student comprehension of the bohr model of the atom, bond polarity, and hybridization. J. Chem. Educ. 2016; 93(9): 1591-1594.

[9] Canessa E. Low-cost 3D printing for science, education and sustainable development. In: Canessa, E.; Fonda, C.; Zennaro, Ed(s). Low-cost 3D Printing. The Abdus Salam International Centre for Theoretical Physics. 2013. 199 p.

[10] Calcabrini M, Onna D. Exploring the gel state: optical determination of gelation times and transport properties of gels with an inexpensive 3D-printed spectrophotometer. J. Chem. Educ. 2019; 96(1): 116-123.

[11] Carroll FA, Blauch DN. 3D printing of molecular models with calculated geometries and $p$ orbital isosurfaces. J. Chem. Educ. 2017; 94(7): 886-891.

[12] Cataldo R, Griffith KM, Fogarty. Hands-on hybridization: 3D-printed models of hybrid orbitals. J. Chem. Educ. 2018; 95(9): 1601-1606.

[13] Fourches D, Feducia J. Student-guided three-dimensional printing activity in large lecture courses: a practical guideline. J. Chem. Educ. 2019; 96(2): 291-295.

[14] Jones OAH, Spencer MJS. A simplified method for the 3D printing of molecular models for chemical education. J. Chem. Educ. 2018; 95(1): 88-96.

[15] Gilbert JK. Representations and models: aspects of scientific literacy. In: Tytler R, Prain V, Hubber P, Waldrip B. Ed(s). Constructing Representations to Learn in Science. Rotterdam: Sense Publishers; 2013.

[16] Linenberger KJ, Bretz SL. Biochemistry students`ideas about how an enzyme interacts with a substrate. Biochem, Mol. Biol. Educ. 2015; 43(4): 213-222.

[17] Sangiogo FA, Zanon LB. Reflexões sobre modelos e representações na formação de professores com foco na compreensão conceitual da catálise enzimática. QNEsc. 2012; 34(1): 26-34.

[18] Pérez GM, Galindo AAG, Galli LG. Enseñanza de la evolución: fundamentos para el diseño de uma propuesta didáctica basada em la modelización y la metacognición sobre los obstáculos epistemológicos. Rev. Eureka sobre Enseñanza y Divulgación de lãs Ciencias. 2018; 15(2): 2102.

[19] Justi R, Gilbert JK. Teachers' views on the nature of models. Int. J. Sci. Educ. 2003; 25(11): 1369-1386.

[20] Griffith KM, Cataldo R, Fogarty KH. Do-it-yourself: 3D models of hydrogenic orbitals through 3D printing. J. Chem. Educ. 2016; 93(9): 1586-1590.

[21] Kaliakin DS, Zaari RR, Varganov. 3D printed potential and free energy surfaces for teaching fundamental concepts in physical chemistry. J. Chem. Educ. 2015; 92(12): 2106-2112.

[22] Meyer SC. 3D printing of protein models in an undergraduate laboratory: leucine zippers. J. Chem. Educ. 2015; 92(12): 2120-2125.

[23] Scalfani VF, Vaid TP. 3D printed molecules and extended solid models for teaching symmetry and point groups. J. Chem. Educ. 2014; 91(8): 1174-1180.

[24] Brown A. 3D printing in instructional settings: identifying a curricular hierarchy of activities. Assoc. for Educ. Communications Technology. 2015; 59(5): 16-24.

[25] Vaz M, Choupina A. Lipases: biocatalizadores da hidrólise de triacilglicerois. Revista Eletrônica de Biologia. 2012; 5(3): 42-58.

[26] Muri EMF. Proteases virais: importantes alvos terapêuticos de compostos peptideomiméticos. Química Nova. 2014; 37(2): 308-316.

[27] Creswell JW. Investigação qualitativa e projeto de pesquisa: escolhendo entre cinco abordagens. 3 Ed. São Paulo: Penso; 2014. 
National award: Construction of 3D Models printed as strategy for learning the concept of enzyme-substrate interaction

[28] Sakabe NJ, Marson GA, TORRES BB. Estudo interativo da estrutura e função de proteínas. Biblioteca Digital de Ciências; 2006. [acesso em 09 Jul. 2018]. Disponível em: https://www.bdc.ib.unicamp.br/bdc/visualizarMaterial.php?idMaterial=247.

[29] Galembeck E, Pedroso Filho CES. Enzyme. Biblioteca Digital de Ciências; 2007. [acesso em 09 Jul. 2018]. [acesso em 09 Jul. 2018]. Disponível em: tps://www2.ib.unicamp.br/lte/bdc/visualizarMaterial.php? idMaterial=528\&nL=723\#.WyBnYtQrLiw.

[30] Galembeck E, Pedroso Filho CES, Torres BB. A cinética da reação enzimática. Biblioteca Digital de Ciências; 2007. [acesso em 09 Jul. 2018]. [acesso em 09 Jul. 2018]. Disponível em: https://www.bdc.ib.unicamp.br/bdc/visualizarMaterial.php?idMaterial=527.

\section{Agradecimentos}

À Universidade Federal de Alfenas pelo suporte oferecido para realização desta pesquisa e aos integrantes do Laboratório de Pesquisa em Educação Química da UNIFAL-MG pelas sugestões para melhoria deste trabalho. 
National award: Construction of 3D Models printed as strategy for learning the concept of enzyme-substrate interaction

Apêndice A. Roteiro para o uso do software AutoCad®.

As etapas descritas a seguir se referem às sequências de comandos necessários para elaboração dos modelos 3D impressos.

1. Realizar a configuração do template do software selecionando o modo "3D modeling";

2. Especificar no software a unidade adequada ao programa de impressão que deve ser em milímetros;

3. Desenhar uma base para o desenho contendo as medidas exatas em relação às dimensões e capacidade da impressora (no caso da impressora utilizada "Cube 3D Printer" as medidas não podem passar de $140 \times 140 \mathrm{~mm}$ );

4. Escolher as medidas da altura máxima, largura e comprimento do desenho. Vale ressaltar que quanto maior for o tamanho da peça, maior será o consumo de PLA;

5. Utilizar o comando "Line" para elaboração dos modelos 3D;

6. Após elaborar os desenhos utilizar o comendo "Join" para unir as linhas do desenho;

7. Utilizar o comando "Splini" para os desenhos de formato não linear;

8. Selecionar o comando de "Extrusão" para obter o formato tridimensional do desenho;

9. Utilizar o comando "Shade" para preenchimento sólido do desenho (esse procedimento confere maior resistência ao modelo);

10. Salvar o desenho elaborado no formato de arquivo stl. 
National award: Construction of 3D Models printed as strategy for learning the concept of enzyme-substrate interaction

Apêndice B. Roteiro para o uso da impressora 3D.

Antes do procedimento de impressão recomenda-se a limpeza do cartucho da impressora para reciclagem do filamento de PLA, evitando o entupimento e o não funcionamento da impressora. As etapas descritas a seguir se referem às sequências de comandos necessários para impressão dos modelos 3D.

1. Importar o arquivo do desenho para o Software 3D Cube ${ }^{\circledR}$ Creativity Relmagined (software disponibilizado com a impressora);

2. Selecionar os seguintes comandos: Heal, Orient and Scale, Center, Build e Print, respectivamente. Estes comandos realizam ajustes antes da impressão dos desenhos, por exemplo, o comando "Build" faz "fatias" horizontais, formando camadas do desenho para que, seja reconhecido pelo sistema da impressora em camadas;

3. Espalhar um gel de proteção térmica na base da impressora onde o modelo será impresso;

4. Selecionar o comando "Print" para iniciar o processo de impressão. O tempo de duração das impressões varia entre 1 a 4 horas e está relacionado às dimensões de tamanho do desenho;

5. Aguardar a impressão completa, sem interrupções;

6. Após a impressão deixar a base de vidro com o modelo em uma bacia com água aquecida até desprender do modelo.

Apêndice C. Roteiro de perguntas para a atividade de avaliação dos modelos.

1. Qual representação se aproximou mais do modelo de ajuste induzido?;

2. Qual (is) os elementos (aspectos químicos) em comum nas representações?;

3. Qual (is) elementos (aspectos químicos) que estavam faltando nas representações?;

4. Qual a limitação, pensando no ensino, do uso do modelo 3D elaborado?. 
National award: Construction of 3D Models printed as strategy for learning the concept of enzyme-substrate interaction

\section{Materiais adicionais}

A seguir são listadas algumas sugestões de materiais disponíveis para download e que podem ser utilizadas em atividades de intervenção durante a modelagem.

\begin{tabular}{|c|c|c|}
\hline Material & Descrição & Tipo de arquivo \\
\hline 1 & $\begin{array}{l}\text { Software educacional livre para o "Estudo interativo da relação entre a } \\
\text { estrutura e a função de proteínas". Fonte: Sakabe, Marson e Torres [28]. } \\
\text { Disponível para download e versão on-line em: } \\
\text { https://www2.ib.unicamp.br/lte/bdc/visualizarMaterial.php? } \\
\text { idMaterial=247\#.Wx8wmtQrLiw. }\end{array}$ & Software \\
\hline 2 & $\begin{array}{l}\text { "Enzyme". Software educacional livre que explora textos, imagens, animações } \\
\text { e simulações sobre a estrutura, função e atividade enzimática. Fonte: } \\
\text { Galembeck e Pedroso Filho [29]. Disponível para download e versão on-line } \\
\text { em: } \\
\text { https://www2.ib.unicamp.br/lte/bdc/visualizarMaterial.php? } \\
\text { idMaterial=528\&nL=723\#.WyBnYtQrLiw. }\end{array}$ & Software \\
\hline 3 & $\begin{array}{l}\text { "A cinética da reação enzimática" é um software que simula um experimento } \\
\text { para o estudante explorar a função e estrutura das enzimas, bem como } \\
\text { identificar os fatores que alteravam a atividade enzimática (pH, temperatura, } \\
\text { concentração de substrato). Fonte: Galembeck, Pedroso Filho e Torres [30]. } \\
\text { Disponível para download e versão on-line em: } \\
\text { https://www2.ib.unicamp.br/lte/bdc_uploads/materiais/versaoOnline/ } \\
\text { versaoOnline527_pt/Cinetica_bin/Cinetica.swf. }\end{array}$ & Software \\
\hline 4 & $\begin{array}{l}\text { Software PDB (Protein Data Bank) que pode ser usado para visualização de } \\
\text { representações (imagens) em 3D de enzimas humanas. Neste banco de dados } \\
\text { é possível visualizar as representações das estruturas das enzimas, rotacionar } \\
\text { e identificar os aminoácidos que compõem a estrutura. Disponível em: } \\
\text { https://www.rcsb.org/. }\end{array}$ & Software \\
\hline 5 & $\begin{array}{l}\text { Apresenta-se na Figura } 6 \text { o modelo 3D reelaborado pelo Grupo 1. Este grupo } \\
\text { utilizou papel de seda coloridos para representar a seletividade da enzima pelo } \\
\text { substrato na região do sítio ativo (representado em amarelo). }\end{array}$ & $\begin{array}{l}\text { Modelo 3D } \\
\text { impresso }\end{array}$ \\
\hline
\end{tabular}


National award: Construction of 3D Models printed as strategy for learning the concept of enzyme-substrate interaction

\begin{tabular}{|c|c|c|}
\hline 6 & $\begin{array}{l}\text { Apresenta-se na Figura } 7 \text { o modelo 3D reelaborado pelo Grupo 3. Este grupo } \\
\text { utilizou materiais para adaptações do modelo. Imãs e papel de seda coloridos } \\
\text { foram utilizados para representar as interações eletrostáticas e a seletividade } \\
\text { da enzima pelo substrato. } \\
\text { Figura 8. Modelo 3D final elaborado pelo Grupo 3. Fonte: dados da pesquisa. }\end{array}$ & $\begin{array}{c}\text { Modelo 3D } \\
\text { impresso }\end{array}$ \\
\hline 7 & $\begin{array}{l}\text { Apresenta-se na Figura } 8 \text { o modelo 3D reelaborado pelo Grupo 4. Este grupo } \\
\text { utilizou materiais para adaptações do modelo. Imãs e papel de seda coloridos } \\
\text { foram utilizados para representar as interações eletrostáticas e a seletividade } \\
\text { da enzima pelo substrato. }\end{array}$ & $\begin{array}{c}\text { Modelo 3D } \\
\text { impresso }\end{array}$ \\
\hline
\end{tabular}

